\title{
Biomarcadores Salivales en Pacientes Diagnosticados con Fibrosis Quística, Concepción, 2016
}

\author{
Salivary Biomarkers in Patients Diagnosed with Cystic Fibrosis, Concepción, 2016
}

\author{
Fernanda Gaete O.; Edgardo Astudillo R.; Bastián Rojas E. \& Carmen Narváez Carrasco
}

GAETE, O. F.; ASTUDILLO, R. E.; ROJAS, E. B. \& NARVÁEZ, C. C. Biomarcadores salivales en pacientes diagnosticados con fibrosis quística, Concepción, 2016. Int. J. Odontostomat., 12(1):51-56, 2018.

RESUMEN: El odontólogo como profesional integral del área de la salud, debe tener conocimiento acerca de distintas manifestaciones bioquímicas que pueden tener repercusión en la cavidad oral. El objetivo del trabajo fue determinar las manifestaciones bioquímicas y alteraciones en biomarcadores salivales en la cavidad oral producto de la fibrosis quística o del consumo crónico de medicamentos para el tratamiento de la FQ. Se seleccionó un total de cinco personas con fibrosis quística y cuatro personas sanas, pertenecientes a la ciudad de Concepción en la Octava Región de Chile. Se midió pH salival, capacidad buffer, concentración de proteínas totales, tasa de flujo salival estimulado y se determinó presencia de ciertas enzimas salivales en pacientes que padecen la enfermedad. Se pudo evidenciar que el pH salival en sujetos con fibrosis quística tiende a ser mayor a los valores de referencia, la tasa de flujo salival es mucho menor al igual que la capacidad buffer, la concentración de proteínas totales en saliva se encuentra igual a los valores de referencia y se determinó la presencia biomarcadores salivales a través de la técnica de electroforesis. La fibrosis quística afecta de muchas formas a las personas que la padecen, genera cambios a nivel de los biomarcadores salivales como también en la cavidad oral, por lo que el odontólogo debe estar capacitado para identificar estos cambios y poder tratar de la mejor manera a todo tipo de paciente.

PALABRAS CLAVE: fibrosis quística, biomarcadores, saliva, proteínas totales, pH, electroforesis.

\section{INTRODUCCIÓN}

Una de las enfermedades de menor incidencia en la población es la fibrosis quística; la cual afecta principalmente a los pulmones y al páncreas siendo más frecuente en los grupos de origen caucásico, alcanzando incidencias entre 1 en 2.500 a 1 en 4.000 en recién nacidos vivos, según la constitución étnica de cada país (Sánchez et al., 2001). En Chile no hay estadísticas sistemáticas, sin embargo se estima una incidencia aproximada es de 1 en $4.000 \mathrm{RN}$ pero en los últimos años se ha registrado un aumento notable en el número de casos nuevos (Fielbaum, 2001). Producto del compromiso que tienen estos pacientes con su enfermedad, tienden a dejar de lado el cuidado de la salud bucal por lo que, en la mayoría de los casos, se observan diversas patologías en la cavidad oral. Para los profesionales de la salud, es una obligación tener conocimiento de todo tipo de enfermedades, no solo de la cavidad oral, sino que también enfermeda- des que puedan afectarla, o que hagan variar la forma de atención con ciertos pacientes que las padecen. Debido a esto se hace necesaria la instauración de protocolos de atención para este tipo de pacientes. Se tiene conocimiento de precauciones o complicaciones que podrían tener pacientes con enfermedades más frecuentes dentro de la población, como lo es la hipertensión y diabetes, pero no hay que olvidar aquellas enfermedades con menor prevalencia dentro de la población que también pueden llegar a la consulta dental, y se debe tener el conocimiento suficiente de la enfermedad que padecen para poder atenderlos de la mejor manera, con las precauciones adecuadas y con el enfoque que debedarse a la prevención y tratamiento de los problemas bucales que presente. No es común que un odontólogo reciba en la consulta a un paciente con Fibrosis quística, pero como profesionales integrales se debe saber de qué se tra-

Facultad de Ciencias de la Salud, Universidad del Desarrollo, Concepción, Chile. 
ta la enfermedad y que precauciones se debe tener al momento de atenderlos. Con esta investigación se quiere aportar conocimiento a futuros odontólogos y a los que ya han egresado, para que puedan atender correctamente a estos pacientes. La inclusión de un dentista pediátrico especialista, como parte del equipo multiprofesional para manejar el cuidado de estos niños, sería una ventaja para un mejor cuidado de la cavidad oral de estos pacientes (Narang et al., 2003). Los estudios e investigaciones donde se relaciona la fibrosis quística y la salud bucal son escasos. La saliva es una secreción compleja, proviene de las glándulas salivales mayores (parótida, sublingual y submandibular) y de las glándulas salivales menores (ubicadas en cara ventral de lengua, paladar blando, cara interna de labios, mucosa de mejillas). En su composición están presente enzimas, inmunoglobulinas y un $\mathrm{pH}$ determinado, todos estos son factores que le dan cierta capacidad defensiva frente a las caries. Dentro de las enfermedades asociadas a xerostomía se encuentra la fibrosis quística donde hay desordenes de las glándulas endocrinas (Seif et al., 1997).

\section{MATERIAL Y MÉTODO}

Se realizó un reporte de casos, para determinar alteraciones en biomarcadores salivales y manifestaciones bucales en pacientes diagnosticados con fibrosis quística, en Concepción 2016. Se trabajó con un tamaño muestral de 9 personas. Para tener un indicativo de normalidad en los datos que conciernen a los biomarcadores salivales se trabajó con 4 personas sin fibrosis quística (estándar) ni ninguna otra patología y 5 personas diagnosticadas con fibrosis quística. Se incluyeron hombres y mujeres diagnosticadas con fibrosis quística entre los $10-30$ años de edad con consumo de medicamentos y suplementos alimenticios similares y sin ningún otro tipo de enfermedad. Se excluyeron aquellas personas que no estuvieran en control médi$\mathrm{co}$, que no consumieran medicamentos para el tratamiento de su enfermedad, aquellas que no estuvieran en el rango de edad y que presentaran otras enfermedades aparte de la fibrosis quística.

Se solicitó autorización para realizar el muestreo y toma de fotografías mediante un consentimiento y asentimiento informado y durante la recolección de datos, se resguardó todos los protocolos sanitarios correspondientes. Los procedimientos estuvieron de acuerdo con las normas éticas de la Declaración de Helsinki de 1975, enmendada en el año 2005.
La calibración del operador se realizó con dos muestras de saliva de $6 \mathrm{ml}$ cada una, las cuales sirvieron para practicar la técnica, como también para realizar todos los procedimientos de laboratorio necesarios para este estudio.

Primero se hizo todo el procedimiento de laboratorio en personas sanas sin presencia de enfermedad y luego en personas diagnosticadas con fibrosis quística. La toma de muestras de saliva en personas sanas se hizo en las instalaciones de la Universidad del Desarrollo, mientras que la toma de muestras de saliva en personas con fibrosis quística se realizó en sus propios domicilios y hospitales. Primero se realizó la recolección de saliva estimulada, para esto se les pidió a los pacientes masticar papel de parafilm durante 1 minuto y luego depositar la saliva en tubos de muestra con tapa rosca previamente rotulados para posteriormente depositarlos en un cooler refrigerado para su congelación en el caso de personas con fibrosis quística, para las personas que no presentaban la enfermedad la saliva fue recolectada en la misma universidad por lo que no fue necesario hacer uso del cooler. Para poder cuantificar el volumen de saliva y determinar la tasa de flujo salival, se necesitaron $6 \mathrm{ml}$ de saliva de cada paciente para todo el análisis en el laboratorio. Posterior a esto se dividieron los $6 \mathrm{ml}$ de saliva en tres muestras de $2 \mathrm{~mL}$ mediante el uso de pipetas de vidrio, de las cuales una sola muestra por paciente fue depositada en tubos Eppendorf y congeladas para su preservación.

El primer paso que se realizó fue el análisis de $\mathrm{pH}$ salival con cinta el cual a través de un cambio de coloración indicó el pH aproximado de la muestra, además se analizó con el pH metro, el cual es un método más exacto que permitió conocer el $\mathrm{pH}$ real.

Posterior a esto se determinó la capacidad buffer de la saliva, por lo que se tuvo que preparar una solución de ácido clorhídrico al 0,005 M. Para determinar la capacidad buffer se mezcló en un tubo de ensayo una solución de $1.5 \mathrm{~mL}$ de saliva (extraída con pipeta de vidrio de $2 \mathrm{~mL}$ ) y $1.5 \mathrm{~mL}$ de $\mathrm{HCL}$ (extraída con pipeta de vidrio de $2 \mathrm{~mL}$ ), se esperó por 20 minutos y luego se midió el pH con el pH metro para determinar la capacidad buffer de la saliva.

Para la determinación de proteínas totales se utilizó el método de Biuret, por lo que se prepararon tres soluciones para este procedimiento, solución $A$, B y C. Para la solución A se necesitaron $18,06 \mathrm{~g}$ de tartrato de sodio y potasio $4 \mathrm{H}_{2} \mathrm{O}, 6 \mathrm{~g}$ de $\mathrm{CuSO}_{4} 5 \mathrm{H}_{2} \mathrm{O}$, 
$2 \mathrm{~g}$ de $\mathrm{Kl}, 40 \mathrm{ml}$ de $\mathrm{NaOH} 2 \mathrm{~N}$ y $200 \mathrm{~mL}$ de agua destilada. Para la solución B se usaron $10 \mathrm{~g}$ de $\mathrm{KI}$ y $160 \mathrm{~mL}$ de $\mathrm{NaOH} 2 \mathrm{~N}$ y para la solución $\mathrm{C}$ (preparada en el momento) se usaron $10 \mathrm{ml}$ de solución $\mathrm{A}, 8 \mathrm{ml}$ de solución $B$ y $100 \mathrm{ml}$ de agua destilada. Una vez preparada la solución $C$ en el momento, se extraen $1,5 \mathrm{~mL}$ de solución $\mathrm{C}$ (con pipeta de vidrio de $2 \mathrm{~mL}$ ) y se mezclan con $1,5 \mathrm{~mL}$ de saliva en un tubo de ensayo, se esperan 20 minutos y luego se depositan $2 \mathrm{~mL}$ de esta solución en cubetas plásticas para poder cargarlas en las celdas del espectrofotómetro, esto para poder leer su absorbancia y formular la curva de calibración correspondiente.

Para determinar la presencia de biomarcadores salivales, se empleó el método de electroforesis desnaturalizante en geles de poliacrilamida, se empieza preparando los vidrios, los cuales van a ser los receptores de los geles, se prepara el gel separador de acrilamida al $10 \%$ con volumen final de solución de $5 \mathrm{~mL}$, cuyos componentes son: agua destilada 1,9 $\mathrm{mL}$; acrilamida al $30 \% 1,7 \mathrm{ml}$; tris $1,5 \mathrm{M} \mathrm{pH} 8,81,3$ $\mathrm{mL}$; SDS al $10 \% 0,05 \mathrm{ml}$; persulfato de amonio al 10 $\%$ 0,03 mL y TEMED 0,003 mL; esta solución se deja gelificar por 60 minutos. Para el gel concentrador se utilizó: agua destilada 2,75 mL; acrilamida al $30 \% 0,85$ $\mathrm{mL}$; tris 1,5 M pH 8,8 $1.3 \mathrm{~mL}$; SDS al $10 \% 0,05 \mathrm{~mL}$; persulfato de amonio al $10 \% 0.03 \mathrm{~mL}$ y TEMED 0.003 $\mathrm{ml}$. Se deja gelificar por 45 minutos.

Se introdujeron ambos geles en la cámara de electroforesis vertical y se deposita solución buffer de corrida compuesto por: Tris base 3,038 mg; glicina $15,01 \mathrm{mg}$; SDS $1 \mathrm{~g}$; en el interior de la cámara y los geles utilizando una micropipeta. Para el proceso de sembrado se tomaron muestras salivales de 4 sujetos sanos sin FQ y 5 de sujetos con FQ, de las cuales se utilizan 15 ul de muestra salival con 10 ul de buffer de muestra: tris $0,5 \mathrm{M} \mathrm{pH} 6,82,5 \mathrm{~mL}$; SDS al $10 \%$ 2,5 mL; 2-mercaptoetanol 2,5 mL; glicerol 2,5 $\mathrm{mL}$ y azul de bromofenol $1 \mathrm{mg}$; se depositaron en tubos eppendorf de 1, $5 \mathrm{ml}$, los cuales se calentaron a baño maría por 5 minutos y luego se centrifugaron por 10 segundos, la totalidad de las muestras obtenidas se sembraron en los pocillos presentes en el gel concentrador utilizando un micropipeta de $50 \mu$ l. Se cierra la cámara de electroforesis y se conectó a una fuente de poder. Posteriormente se ingresó el voltaje de 35 volts y se dejó correr por 40 minutos hasta que las muestras ingresaron al gel separador, luego se aumentó el voltaje a 65 volts por 2 horas hasta que las muestras recorrieran en su totalidad el gel separador.
Terminados de correr los geles se retiraron de la cámara y se dejaron en una solución de tinción de azul brillante de croomasie: $\mathrm{O}, 50 \mathrm{~g}$ de azul brillante de croomasie en $180 \mathrm{~mL}$ de metanol con $20 \mathrm{~mL}$ de ácido acético glacial. Por 1 hora sobre un shaker eléctrico a una velocidad de $65 \mathrm{rpm}$. Se retiraron con una piseta los excesos de la tinción con agua destilada. Luego los geles se dejaron en una solución de decoloración lenta cuyos componentes fueron ácido acético glacial 20 con $10 \mathrm{ml}$ de metanol. Luego se llevó la solución a 200 con una piseta con 170 con una piseta de agua destilada. Finalmente los geles son escaneados y analizados.

\section{RESULTADOS}

Para la determinación de valores de referencia se utilizaron los resultados de $\mathrm{pH}$ salival, capacidad buffer, flujo salival estimulado (Tabla I), absorbancia y concentración de proteínas totales (Tabla II) de los sujetos sin FQ, calculando promedio y desviación estándar.

Se realizó también la determinación de $\mathrm{pH}$ salival, capacidad buffer, flujo salival estimulado (Tabla III), absorbancia y concentración de proteínas totales (Tabla IV) de los sujetos con Fibrosis Quística, calculando promedio y desviación estándar.

En la Figura 1 se observa presencia de enzimas salivales en gel de poliacrilamida en pacientes con y sin FQ con marcador de peso molecular de 250 - $10 \mathrm{kDa}$. La distribución de las celdas se muestra en la tabla que esta junto a la Figura 1.

Se indica presencia de distintas enzimas salivales según intervalo de peso molecular, en gel donde se utilizó marcador de peso molecular de 250 - $10 \mathrm{kDa}$ (Tabla V).

En la figura 2 se observa presencia de enzimas salivales en gel de poliacrilamida en pacientes con y sin FQ con marcador de peso molecular de 250-60 kDa. La distribución de las celdas se muestra en la tabla que esta junto a la Figura 2.

Se indica presencia de distintas enzimas salivales según intervalo de peso molecular, en gel donde se utilizó marcador de peso molecular de 250-60 kDa (Tabla VI). 
Tabla I. Resultado pH salival, capacidad buffer, y flujo salival estimulado en pacientes sanos.

\begin{tabular}{|c|c|c|c|c|}
\hline Códigos sujetos & $\begin{array}{lr}\mathrm{pH} & \text { saliva } \\
\text { estimulada } & \text { (uso } \\
\text { de cinta) } & \\
\end{array}$ & $\begin{array}{lr}\mathrm{pH} & \text { saliva } \\
\text { estimula (con } \\
\text { pH metro) }\end{array}$ & $\begin{array}{l}\text { Cap, } \\
\text { Buffer (pH) }\end{array}$ & $\begin{array}{l}\text { Flujo salival } \\
\text { estimulado } \\
\text { (ml/min) }\end{array}$ \\
\hline 1 & 7,00 & 7,04 & 5,65 & 4 \\
\hline 2 & 7,00 & 7,09 & 6,56 & 4,1 \\
\hline 3 & 7,00 & 6,92 & 6,30 & 2 \\
\hline 4 & 7,00 & 7,07 & 6,15 & 3,36 \\
\hline Promedio & 7,00 & 7,03 & 6,16 & 3,36 \\
\hline $\begin{array}{l}\text { Desviación } \\
\text { Estándar }\end{array}$ & 0,00 & 0,07 & 0,38 & 0,96 \\
\hline
\end{tabular}

\begin{tabular}{|l|l|}
\hline Celda & Sujeto \\
\hline 1 & PM \\
\hline 2 & 1 \\
\hline 3 & 2 \\
\hline 4 & 3 \\
\hline 5 & 4 \\
\hline 6 & 5 \\
\hline 7 & 6 \\
\hline 8 & 7 \\
\hline 9 & 8 \\
\hline 10 & 9 \\
\hline
\end{tabular}

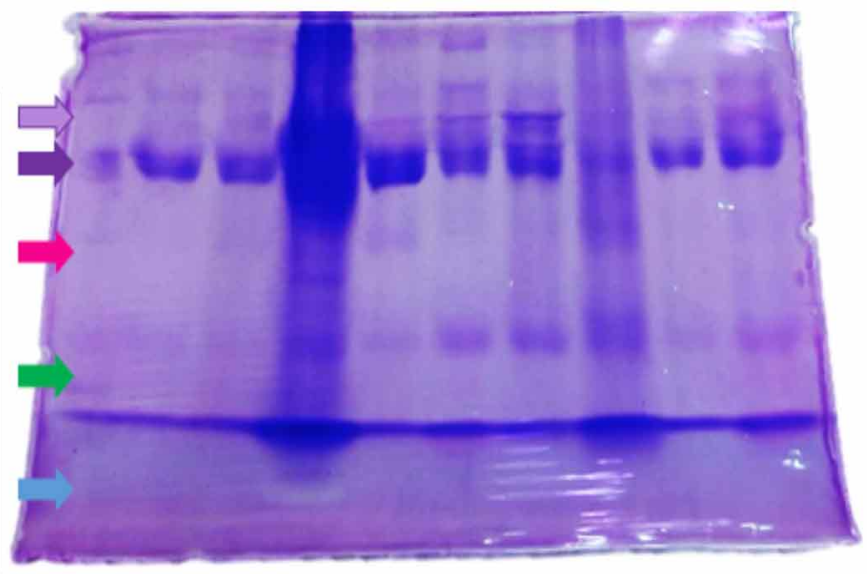

Fig. 1. Muestras salivales de sujetos con y sin fibrosis quística en gel de poliacrilamida con Marcador de peso molecular de 250 - $10 \mathrm{kDa}$.

Tabla Il. Resultado Absorbancia y concentración de proteínas totales en personas sin fibrosis quística.

\begin{tabular}{lcc}
\hline Códigos sujetos & Absorbancia & Concentración Proteínas Totales $(\mathrm{g} / \mathrm{L})$ \\
\hline 1 & 0,920 & 8,4 \\
2 & 0,422 & 3,1 \\
3 & 0,445 & 3,4 \\
4 & 1,581 & 15,3 \\
\hline Promedio & 0,635 & 7,55 \\
\hline Desviación Estándar & 0,650 & 5,70 \\
\hline
\end{tabular}

Tabla III. Resultado pH salival, capacidad buffer, y flujo salival estimulado en pacientes con FQ.

\begin{tabular}{lcccc}
\hline Códigos sujetos & $\begin{array}{c}\mathrm{pH} \text { saliva } \\
\text { estimu lada } \\
\text { (uso de cinta) }\end{array}$ & $\begin{array}{c}\mathrm{pH} \text { saliva } \\
\text { estimula (con } \mathrm{pH} \\
\text { metro) }\end{array}$ & $\begin{array}{c}\text { Cap, Buffer } \\
(\mathrm{pH})\end{array}$ & $\begin{array}{c}\text { Flujo saliva } \\
\text { estimuladc } \\
\text { (ml/min) }\end{array}$ \\
\hline 5 & 7,00 & 6,97 & 4,07 & 0,40 \\
6 & 7,00 & 7,25 & 6,10 & 0,32 \\
7 & 8,00 & 7,55 & 5,50 & 0,41 \\
8 & 7,00 & 6,91 & 6,76 & 0,53 \\
9 & 7,00 & 7,1 & 6,71 & 0,47 \\
\hline Promedio & 7,02 & 7,15 & 5,82 & 0,42 \\
\hline Desviación estándar & 0,44 & 0,25 & 1,10 & 0,07 \\
\hline
\end{tabular}


Tabla IV. Resultado Absorbancia y concentración de proteínas totales en personas con fibrosis quística.

\begin{tabular}{lcc}
\hline Códigos sujetos & Absorbancia & Concentración Proteínas Totales $(\mathrm{g} / \mathrm{L})$ \\
\hline 5 & 0.374 & 2.6 \\
6 & 2.227 & 22.1 \\
7 & 1.17 & 11 \\
8 & 0.672 & 5.8 \\
9 & 0.496 & 3.9 \\
\hline Promedio & 0.987 & 9.08 \\
\hline Desviación Estándar & 0.756 & 7.94 \\
\hline
\end{tabular}

Tabla V. Resultado: presencia de enzimas salivales en gel de poliacrilamida en pacientes con y sin FQ con Marcador de peso molecular de 250 - $10 \mathrm{kDa}$.

\begin{tabular}{|c|c|c|c|c|c|c|c|c|c|c|}
\hline Celda & $1(\mathrm{kDa})$ & 2 & 3 & 4 & 5 & 6 & 7 & 8 & 9 & 10 \\
\hline Enzimas & $150-200$ & MUC2 & MUC2 & MUC2 & MUC2 & MUC2 & MUC2 & MUC2 & MUC2 & MUC2 \\
\hline \multirow[t]{5}{*}{ Salivales } & $75-78$ & & & Lactoferrina & Lactoferrina & Lactoferrina & & Lactoferrina & & Lactoferrina \\
\hline & & & & Peroxidasa & Peroxidasa & Peroxidasa & & Peroxidasa & & Peroxidasa \\
\hline & $45-60$ & & & A. Carbonica & A. Carbonica & A. Carbonica & A. Carbonica & A. Carbonica & A. Carbonica & A. Carbónica \\
\hline & & & & Amilasa & Amilasa & Amilasa & Amilasa & Amilasa & Amilasa & Amilasa \\
\hline & $15-20$ & & & Prolactina & & & & Prolactina & & Prolactina \\
\hline
\end{tabular}

Tabla VI. Resultado: presencia de enzimas salivales en gel de poliacrilamida en pacientes con y sin FQ con Marcador de Peso molecular de 250-60 kDa.

\begin{tabular}{lllllllll}
\hline Celda & $1(\mathrm{kDa})$ & 2 & 3 & 4 & 5 & 6 & 7 & 9 \\
\hline Enzimas & $150 \mathrm{kDa}$ & MUC2 & MUC2 & MUC2 & MUC2 & MUC2 & MUC2 & MUC2 \\
Salivales & $75-78$ & Lactoferrina & Lactoferrina & Lactoferrina & Lactoferrina & Lactoferrina & Lactoferrina & Lactoferrina \\
& & Peroxidasa & Peroxidasa & peroxidasa & Peroxidasa & Peroxidasa & Peroxidasa & Peroxidasa \\
\hline
\end{tabular}

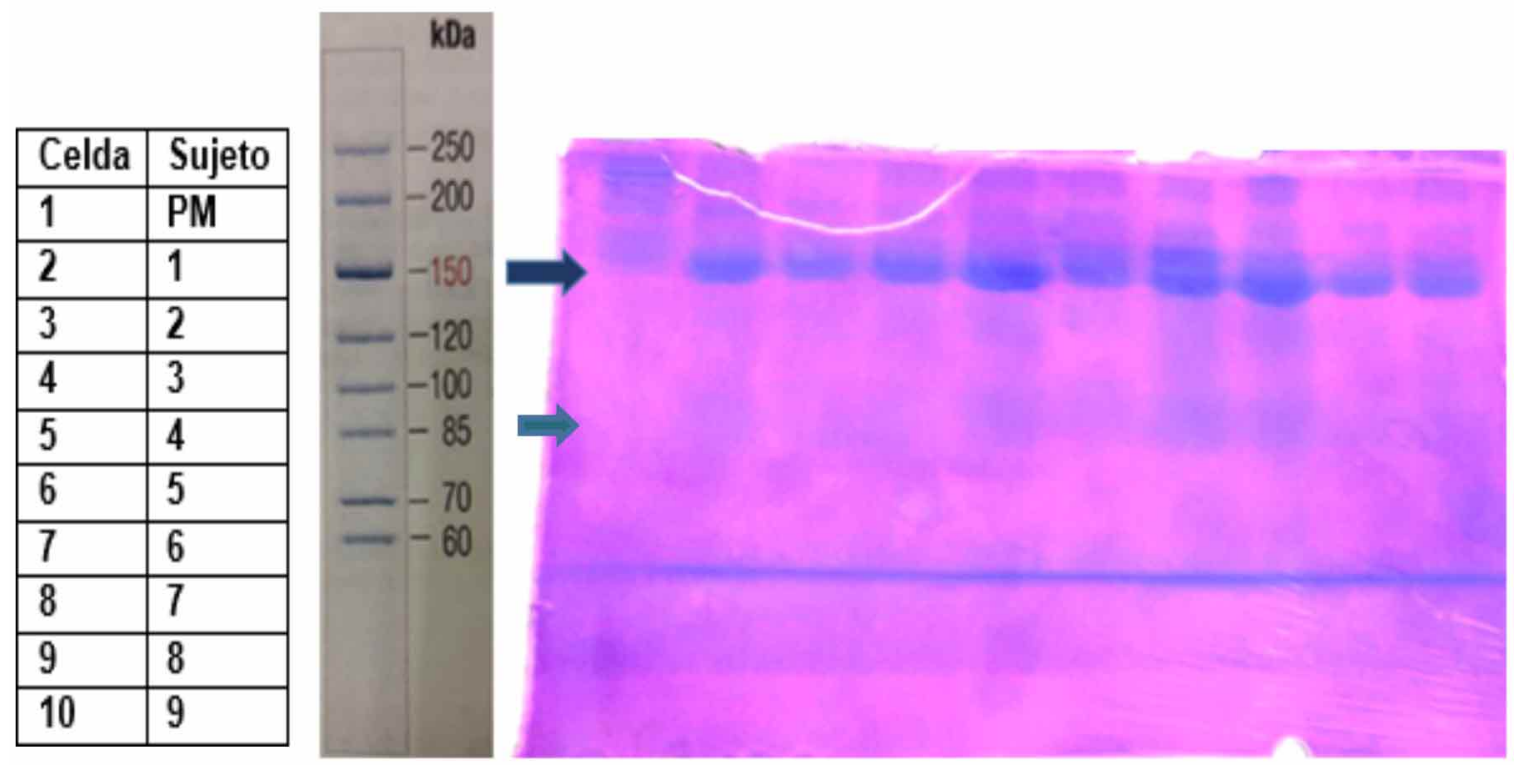

Fig. 2. Muestras salivales de sujetos con y sin fibrosis quística en gel de poliacrilamida con Marcador de Peso molecular de 250-60 kDa. 


\section{DISCUSIÓN}

En la actualidad es crucial para el odontólogo tener un mayor conocimiento sobre las distintas enfermedades que pueden afectar a sus pacientes como lo es el caso de la fibrosis quística y de esta forma poder brindar una mejor atención dental. Esta enfermedad presenta muchas alteraciones en relación a la saliva y también a las manifestaciones que podemos encontrar en la cavidad oral, por lo que se debe tener en cuenta sus características al momento de determinar los tratamientos a realizar. Los hallazgos de este estudio demuestran que los sujetos con $\mathrm{FQ}$ presentan un $\mathrm{pH}$ salival más alcalino, capacidad buffer disminuida, una peor higiene bucal y una menor tasa de flujo salival estimulado, comparándolo con los valores de referencia, lo que puede generar una mayor cantidad de tártaro e inflamación gingival, y una menor prevalencia de caries dental, lo que concuerda con investigaciones anteriores (Kinirons, 1989). A través del método de electroforesis en geles de poliacrilamida se pudo determinar la presencia de varias enzimas salivales de alto y bajo peso molecular importantes en la saliva, como lo son la mucina, amilasa, lisozima, entre otras.

La saliva de los pacientes con FQ tenía tendencia a ser más viscosa a diferencia de la saliva de pacientes sin $F Q$, esto se observó cuando se cargaban las celdas o cuando se mezclaba o diluían en alguna solución. Con estos resultados obtenidos se busca otorgar nuevos conocimientos sobre la enfermedad, realizar el enfoque terapéutico necesario que se debe dar a estos pacientes para lograr que tengan una salud bucal optima e implementar a futuro nuevos protocolos de atención, incluyendo las precauciones que se debe tener al momento de atender a pacientes con FQ.

AGRADECIMIENTOS. Para Patricio y Mario Merino Astudillo, también a todos los niños que padecen Fibrosis Quística y sus padres luchadores, que nos ayudaron a llevar a cabo esta investigación.

GAETE, O. F.; ASTUDILLO, R. E.; ROJAS, E. B. \& NARVÁEZ, C. C. Salivary biomarkers in patients diagnosed with cystic fibrosis, Concepción, 2016. Int. J. Odontostomat., 12(1):51-56, 2018.

ABSTRACT: The dentist as an integral health professional must have knowledge of various biochemical manifestations that may have repercussions on the oral cavity. The objective of the study was to determine the biochemical manifestations and salivary biomarker alterations in the oral cavity resulting from cystic fibrosis or chronic consumption of drugs for the treatment of CF. We selected a total of five people with cystic fibrosis and four healthy people, from the city of Concepcion in the eighth region of Chile. Salivary $\mathrm{pH}$, buffer capacity, total protein concentration, stimulated salivary flow rate and the presence of certain salivary enzymes were measured in patients suffering from the disease. It was observed that the salivary $\mathrm{pH}$ in subjects with cystic fibrosis tends to be higher than the reference values, the salivary flow rate and buffer capacity are less than normal, the total protein concentration in saliva is equal to the reference values and the presence of salivary biomarkers was determined through the electrophoresis technique. Cystic fibrosis affects those who suffer the disease in many ways, it generates changes at the salivary biomarker level, as well as in the oral cavity. The dentist must therefore, be able to identify these changes in order to treat them in the best possible approach for all types of patients.

KEY WORDS: cystic fibrosis, biomarkers, saliva, total proteins, $\mathrm{pH}$, electrophoresis.

\section{REFERENCIAS BIBLIOGRÁFICAS}

Fielbaum, O. Avances en fibrosis quística. Rev. Med. Clin. Condes, 22(2):150-9, 2011.

Kinirons, M. J. Dental health of patients suffering from cystic fibrosis in Northern Ireland. Community Dent. Health, 6(2):113-20, 1989.

Narang, A.; Maguire, A.; Nunn, J. H. \& Bush, A. Oral health and related factors in cystic fibrosis and other chronic respiratory disorders. Arch. Dis. Child., 88(8):702-7, 2003.

Sánchez, D. I.; Pérez, H. M. A.; Boza, C. M. L.; Lezana, S. V.; Vila, I. M. A.; Repetto, L. G.; Hodgson, B. M. I. \& Ríos, M. G. Consenso nacional de fibrosis quística. Rev. Chile Pediatr., 72(4):35680,2001

Seift, T.; Bóveda, C. et al. Cariología: Prevención, Diagnóstico y Tratamiento Contemporáneo de la caries dental. Actualidades Médico Odontológicas Latinoamérica, Bogotá. Cap. 8:219, 2997.

Dirección para correspondencia:

BQ. Carmen Gloria Narváez C.

Directora Cs. Básicas, Met. e Investigación

Universidad del Desarrollo

Concepción

CHILE

Email: cgnarvaez@udd.cl

Recibido : $14-07-2017$

Aceptado: $23-12-2017$ 